\title{
Plant processing in the Late Mesolithic Poland: in search for function of the mysterious 'curved knives'
}

\author{
Grzegorz Osipowicz $^{1}$ (D)
}

Received: 28 October 2018 / Accepted: 9 January 2019 /Published online: 24 January 2019

(C) The Author(s) 2019

\begin{abstract}
Studies on the treatment and use of plants in the Mesolithic are difficult due to the small number of sources. However, they are important because it was one of the basic branches of the economy of the early Holocene community. This article presents the results of use-wear and experimental studies aimed at the interpretation of the function of the so-called curved knives. These tools are associated with the treatment of silica plants, but their actual function is not fully understood. The research was based on a collection of 66 products of this type from five sites in central Poland and is one of the first published research on tools of this kind from this part of Europe. As a result of microscopic analysis, eight types of curved knives were distinguished. In order to identify the plant species, the knives were used on an experimental programme based on the results of palynological studies carried out at site 6 in Ludowice, an economically specialised site. As a result of the traceological analyses, a number of correlations between artefacts and experimental tools have been identified that can provide an important step towards interpreting the actual function of the curved knives. At the same time, the large discrepancies in the traces resulting from the processing of different species of silica plants were documented and the probable use of many of their species in the European Mesolithic was suggested.
\end{abstract}

Keywords Mesolithic $\cdot$ Silica plants processing $\cdot$ Use wear $\cdot$ Curved knives $\cdot$ Poland

The beginning of the Holocene was a time of transition in the economic activity of humans inhabiting the area of the North European Plain. Glacier recession and changes in the natural environment allowed many branches of economic activity to develop; the most prominent of which was gathering and using herbaceous plants, including species with a high silica content. There is evidence of the processing of these species in the Late Glacial period (Sobkowiak-Tabaka and KufelDiakowska 2018), but its rapid development is dated to the Early Holocene. Unambiguous evidence for the high importance of plant material (including high-silica-content species) in that period is provided primarily by peat site finds (Gramsch 1992; Lozovski et al. 2013; Zhilin 2014; Taylor et al. 2018). Use-wear analyses of flint tools can provide some indication of the extent of the phenomenon and the type of plants used; however, wear traces formed as a result of this type of activity are highly diverse and difficult to interpret.

Grzegorz Osipowicz

grezegor@umk.pl

1 Institute of Archaeology, Nicolaus Copernicus University, Szosa Bydgoska 44/48 st., 87-100 Toruń, Poland
A very interesting type of the tools associated with the processing of siliceous plants during the Early Holocene is sometimes referred to as curved knives (Juel Jensen 1994; Guéret 2013). The use of this term indicating a certain separateness of these tools from the other ones used for processing plants seems to be the most appropriate, because it allows characterisation (within one group) of the artefacts bearing unique and linking usage traces that distinguish them from, e.g. ordinary knives for cutting plants. In terms of morphology, these are usually relatively large blades or flakes with naturally concave or (less often) straight lateral edges used for working. Traces recorded on them indicate that they were used at $45-90^{\circ}$ angles and that the tools were held in a perpendicular or slanted position. Previous studies allowed two morphological types of these tools to be distinguished, those with microdenticulated and those (the 'proper' curved knives) with natural working edges (Juel Jensen 1994). Most of them come from West European settlements dated to the Late Mesolithic and the Early Neolithic, usually connected to Kongemose and Ertebølle cultures (van Gijn 1989, 2010; Juel Jensen 1994; Little and van Gijn 
2017). However, some of the tools were also found at sites dated to the early Mesolithic (Beugnier and Crombé 2005; Beugnier 2007; Guéret 2013).

Single tools of this type originating from Poland were already initially presented by the author of this article (Osipowicz 2010). Also, Katarzyna Pyżewicz described some Mesolithic artefacts for plants processing from western Poland, analysing collections of flint products from the sites of Jastrzębia Góra 4 and Turowiec 3 (Pyżewicz 2013). The characteristics of use-wear observed on these tools presented by the author are, however, too general to be sure how often and exactly in which cases we are dealing with the curved knives, especially, that the function of these artefacts is often interpreted different (for example as whittling knives for wood processing).

In the past, tools of this type were associated with the treatment of very different materials, for example plant fibres (shoots or stems of plants containing silica), hide with the addition of ochre, mud or other abrasive materials, the ochre itself, bone and antler. To interpret the function of curved knives and microdenticulates, experiments were undertaken peeling rhizomes, de-barking different types of soft wood, opening hazelnuts and peeling tubers of lily and water stick (van Gijn 1989, 2010; Juel Jensen 1994; Hurcombe 2008; Little and van Gijn 2017). Traces similar to those found on the curved knives were also described by Vaughan (1985) who characterised the nature of damages formed during experimental scraping/planing of cane. At present, the results of the experiments appear to confirm the opinion of most researchers (Vaughan and Bocquet 1987; Juel Jensen 1994; Hurcombe 2008; van Gijn 2010; Guéret et al. 2014; Little and van Gijn 2017), indicating a possible relationship between these tools and work in non-wooden-like material, exhibiting a high content of silica. The arrangement of registered striations points to an activity similar to planing, possibly splitting.

The aim of the present study was to interpret the actual function of curved knives based on experimental studies and use-wear analyses of this type of tools from several Polish sites, in particular, a complex of Mesolithic settlements specialising in siliceous plant processing excavated at Ludowice 6 site (Osipowicz 2018). This site provided an exceptionally large and diverse collection of the artefacts of this functional type, which allowed wear traces recorded on these tools to be precisely classified and, combined with the findings of the conducted palynological studies, created a possibility to make a correct interpretation of their original function.

\section{Materials and methods}

The material applied in the present study was derived from five Mesolithic sites located in Central Poland, in the Chełmno-Dobrzyń Lakeland (Fig. 1). These are
Ludowice, Wąbrzeźno commune, site 6, Sąsieczno, Obrowo commune, site 4, Lubicz, Lubicz commune, sites 13 and 18 and Paliwodzizna, Golub-Dobrzyń commune, site 29. In total, 66 curved knives were subjected to the use-wear analysis.

The site Ludowice 6 is located in the middle part of the Chełmno Lakeland, within a slope of a hill reaching a height of $100 \mathrm{~m}$ above sea level. It is situated in a contact zone of sandur and a large melt ice depression, presently filled with biogenic sediments (peat). Prehistoric materials found on the examined part of the site formed three concentrations, two of which were Mesolithic. The use-wear analysis was performed on 5129 flints from Mesolithic assemblages most of which were derived from subsoil with some from topsoil. All artefacts have been observed both in macro and microscopic scale. Four hundred four specimens were identified to bear wear traces ${ }^{1}$ and to have been used for 443 functions. Among these, there were 58 curved knives. These constituted the most numerous functional type of all the products of identified purpose and served as one of the grounds for a hypothesis on production speciality of the site (Osipowicz 2010, 2015, 2017, 2018; Osipowicz et al. 2014).

The site Sasieczno 4 is situated within the Torun Basin, around $5 \mathrm{~km}$ from the current Vistula riverbed. The majority of the artefacts found here are associated with the Funnealbeaker Culture settlement. Mesolithic specimens occurred only in its northern part, where four flint scatters were discovered. In total, as much as 4622 flint products were derived at that location; 396 of which were identified in the course of the use-wear analysis to bear wear traces. These were used for 446 functions. This collection included only three curved knives (Osipowicz 2010, 2017).

Sites 13 and 18 in Lubicz are situated in the river valley of the Drwęca in the eastern part of the Torun Plain on a sandy cape of the third fluvial terrace. Site 13 is where 158 flint products were excavated, of which 32 products were identified with wear traces and to have been used for 36 functions. As many as 310 flint products were found on site Lubicz 18, while as a result of a use-wear analysis, 71 products with wear traces were specified, which related to 80 functions (Osipowicz 2010). Two tools for silica plant processing (curved knife and microdenticulate) have been discovered in collections from sites in Lubicz.

Paliwodzizna site 29 is located in a tunnel valley of lakes Grodno and Plebanka in the northern part of the Dobrzyń Lakeland. It is one of several sites in this location examined as part of the project titled: Mesolithic communities of the

\footnotetext{
${ }^{1}$ Including products of uncertain function, i.e. considered used but with no possibility of suggesting their function, as well as those described as probably used.
} 


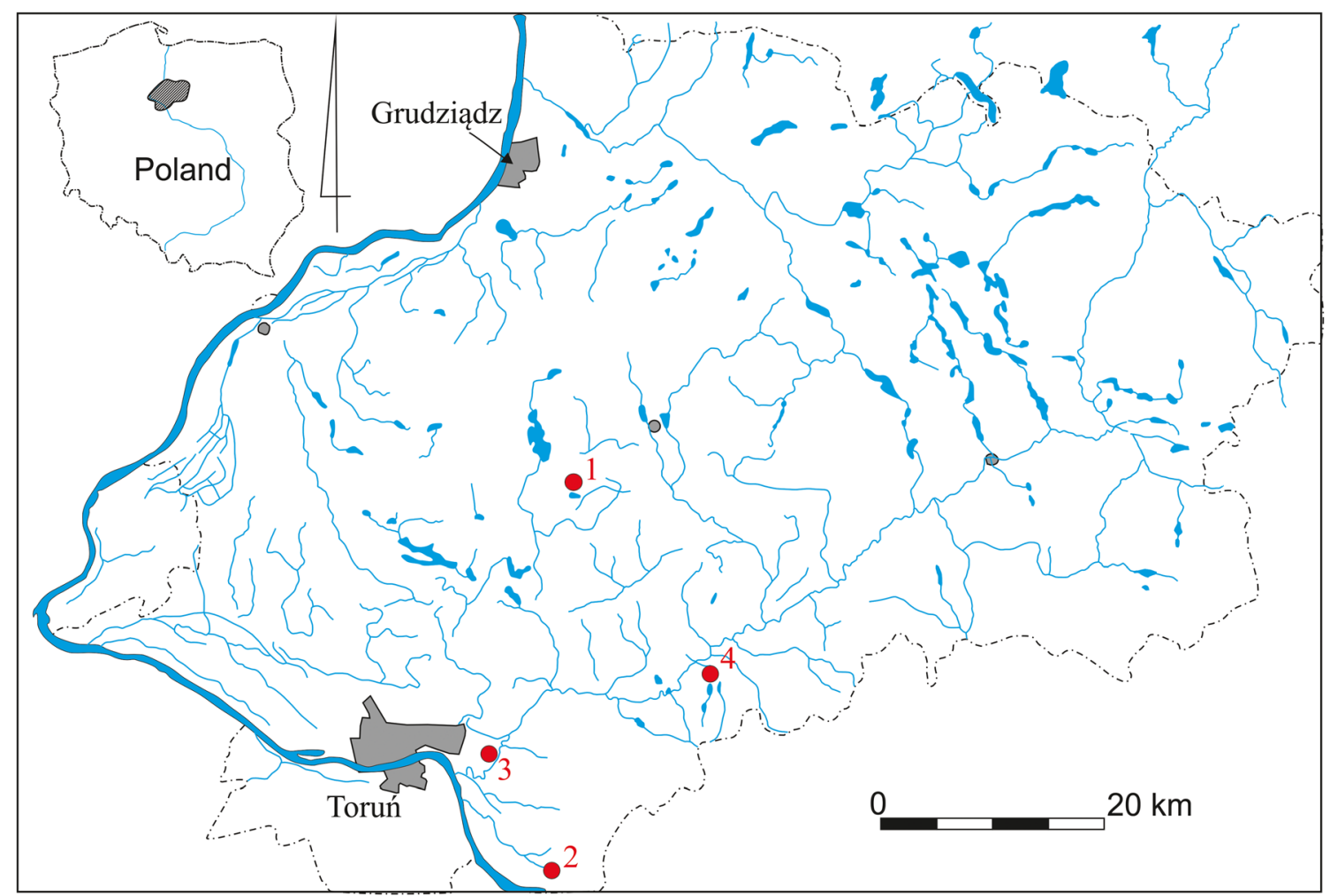

Fig. 1 Location of the sites: 1-Ludowice, Wąbrzeźno comm., site 6; 2-Sąsieczno, Obrowo comm., site 4; 3-Lubicz, gm. Lubicz, stan. 13, 18; 4 Paliwodzizna, Golub-Dobrzyń comm., site 29

Chetmno-Dobrzyń Lakeland - daily life, mobility, external contacts and relationships with the environment, financed by the National Science Center (NCN) in Cracow (Poland) (project no. 2016/23/B/HS3/00689). Excavation works started here in 2016 and have not yet been completed. On the site, numerous remains of Mesolithic and Late Palaeolithic settlements were found. The excavated material is currently subjected to analysis; the results of which will be presented in the near future. The curved knives (three specimens) covered in the paper were identified in the course of preliminary use-wear analyses of parts of flint materials.

Considering the stylistics of the prehistorical materials and the radiocarbon dating results, all the sites can be dated to the Late (Atlantic) Mesolithic (Osipowicz 2010, 2017), whereas the curved knives obtained there do not vary in terms of their form from West European specimens (Fig. 2).

The traceological analyses described in the article were performed using two microscopes. The initial stage was determined under a microscope Nikon SMZ-2T with up to $12,6 \times$ magnitude (virtual manification up to $120 \times$ ). Observations of polish were obtained using a Zeiss-Axiotech microscope, with up to $50 \times$ magnitude (virtual magnification up to $500 \times$ ), fitted with an Axiocam 105 camera. All photomicrographs presented were captured using this equipment. Prior to analysis, the material was cleaned with a detergent diluted in water and pure ethanol $\left(\mathrm{C}_{2} \mathrm{H}_{5} \mathrm{OH}\right)$.

\section{Results}

\section{Classification of wear traces identified on the curved knives}

The fact that many curved knives were identified in the materials from the site in Ludowice allowed a detailed comparative analysis of wear traces visible on the knives. This allowed significant divergences in their characteristics to be recorded and could serve as a basis for a more precise functional classification of this type of tools.

It is assumed that a feature of products of this functional type is the presence of different types of polish on their working edges. These are connected to each other and occur in repeatable patterns. In general, it is believed that on most tools, two types of such patterns are encountered. On non-contact surfaces of the knives, there is a bright polish of a flat topography and rough texture (type A), and/or similar to the polish observed on the tools used for working antler, which is of a domed topography and smooth texture (type B). In turn, on contact surfaces, a linear polish is recorded, which is glossy and of a flat topography (type C) or 'hide' domed polish of type D. Both are accompanied by slanted linear traces in the form of black striations (Juel Jensen 1994; van Gijn 2010; Osipowicz 2010). Among the 
Fig. 2 Examples of the curved knives from the included sites: $1-$ 18-Ludowice, site 6; 19Lubicz, site 13; 20-Lubicz, site 18; 21, 22-Sąsieczno, site 4; 23 25-Paliwodzizna, site 29 Drawnings D. Nowak
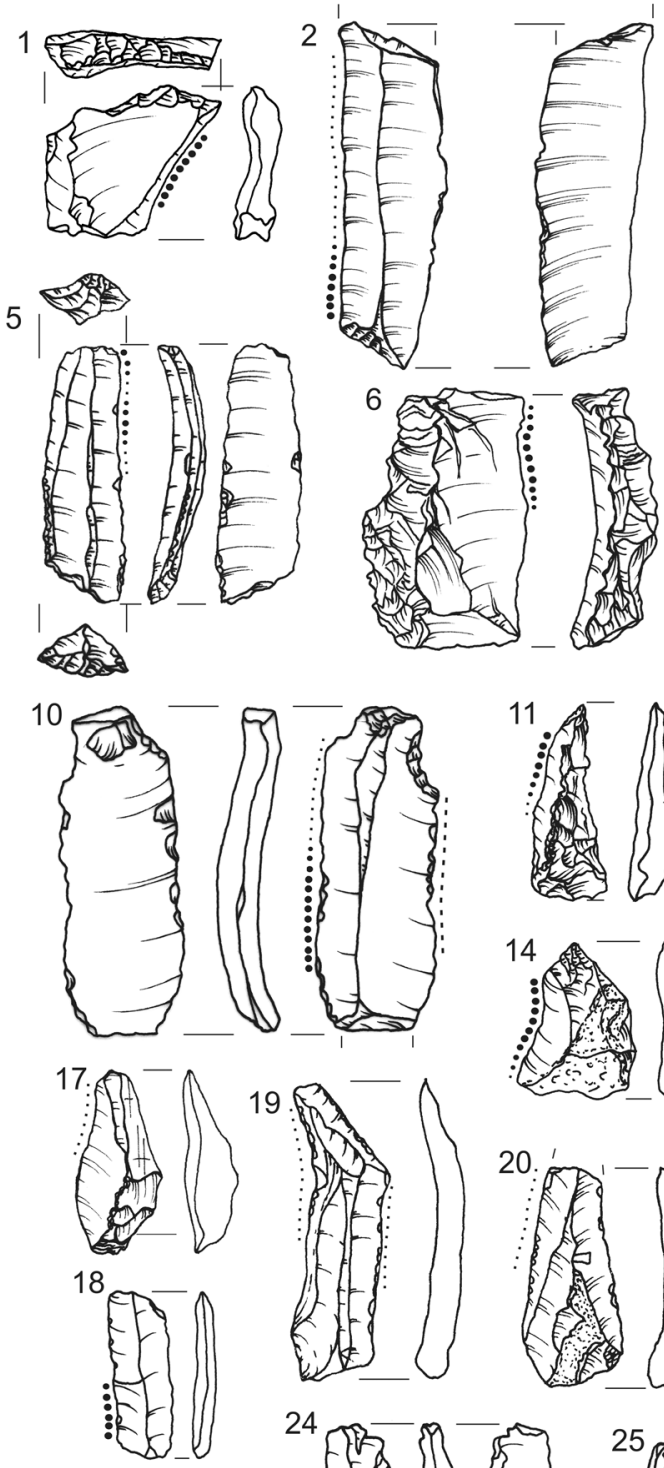

23
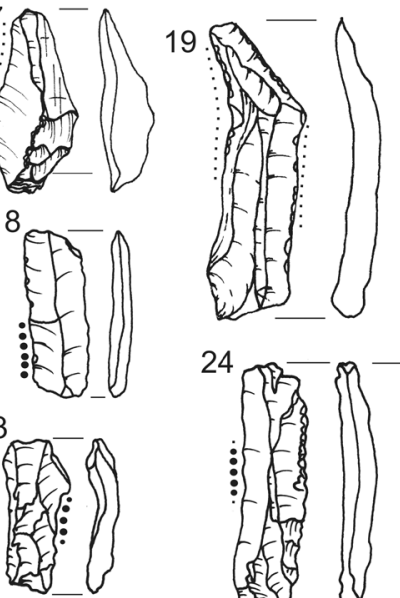
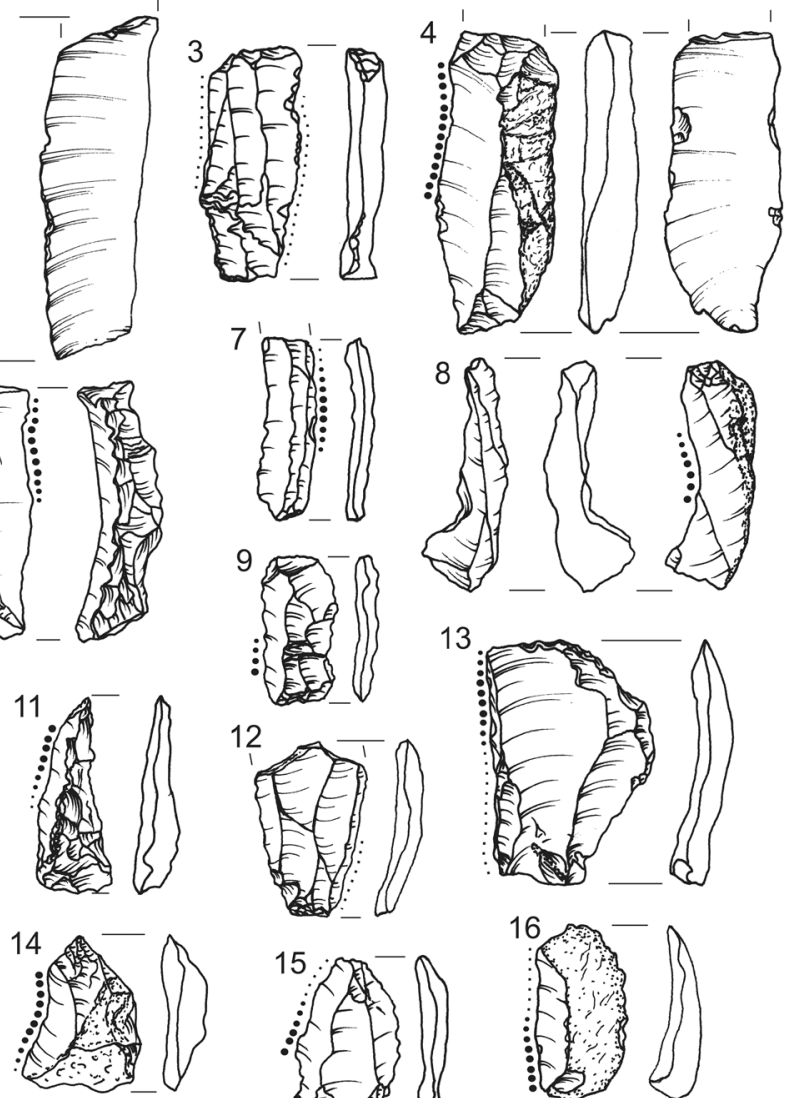

12
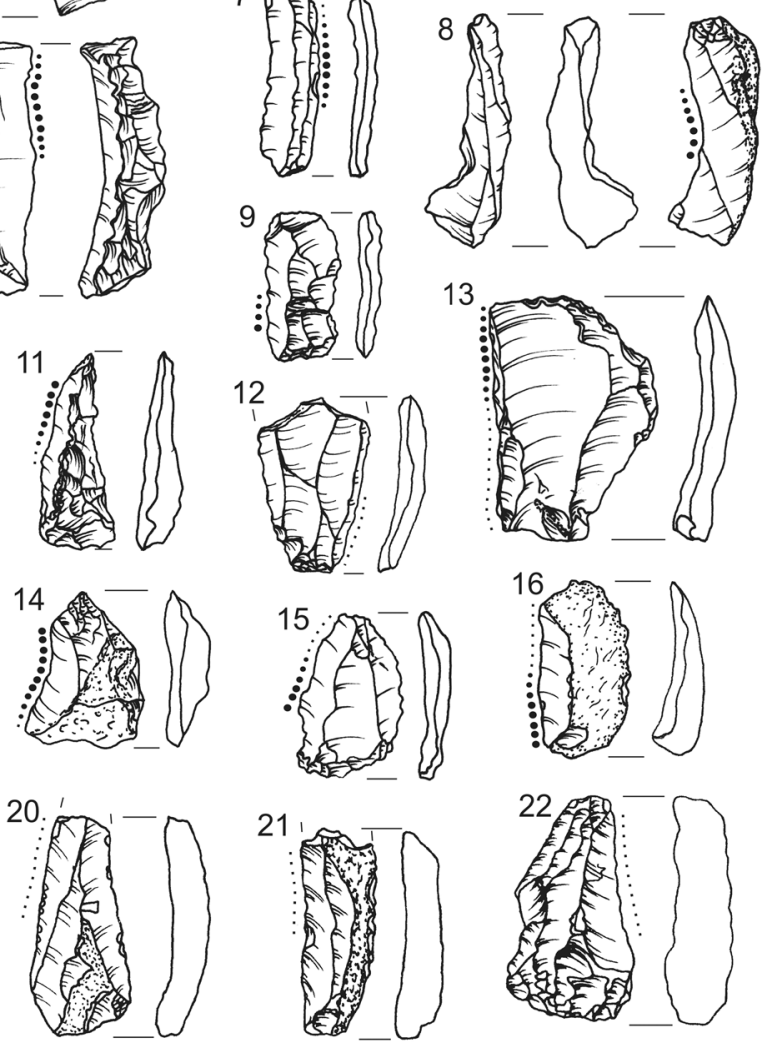

21
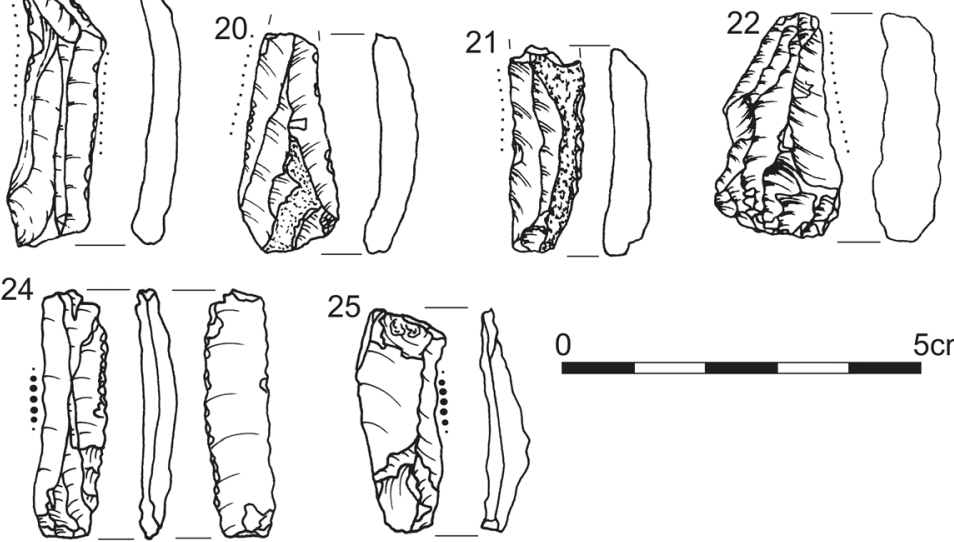

identified tools, the most common are specimens with polish of the A-C and B-D patterns. Products with these sort of traces were relatively numerous also in the materials from the analysed sites. As a result of the conducted usewear analyses, however, curved knives were identified with systems of polish that were substantially different from the adopted 'standards'. For this reason, an attempt was made here to re-classify them, as a result of which, eight main types of these tools were distinguished (compare Table 1). Some of the identified types of polish have already been mentioned by Juel Jensen (1994) and by other researchers.
The working edges of all distinguished types of curved knives bear usually the same type of use retouch (wide/irregular, one-step, built with the single scars with feather terminations). For this reason, it is not discussed in this work.

\section{Type 1}

Curved knives qualified to this type bear on the ventral faces bright, linear polish usually with a marginal (sometimes medium) degree of intrusion, a domed topography that becomes flat (slightly pitted) near the cutting edge with a quite rough 


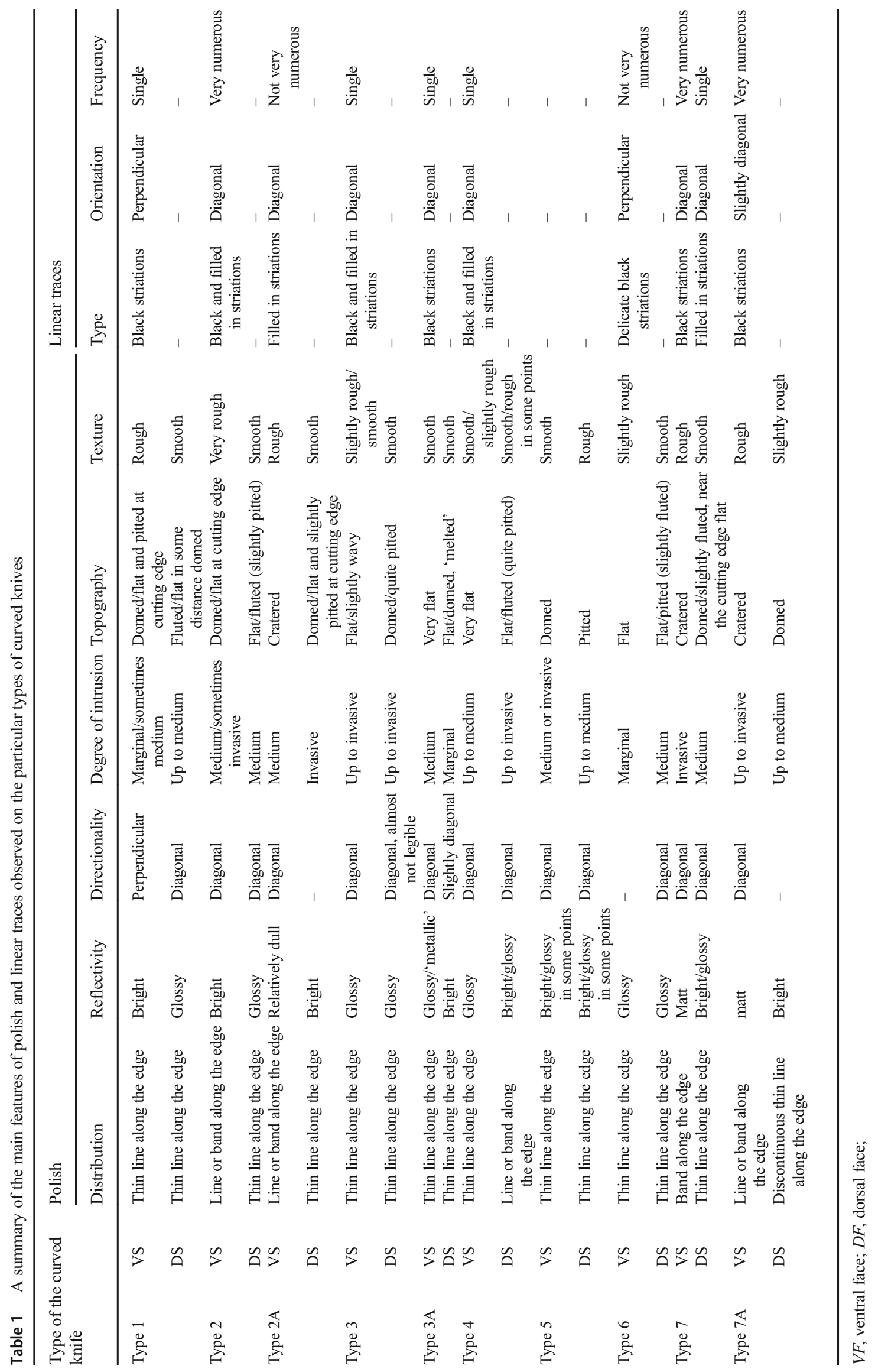



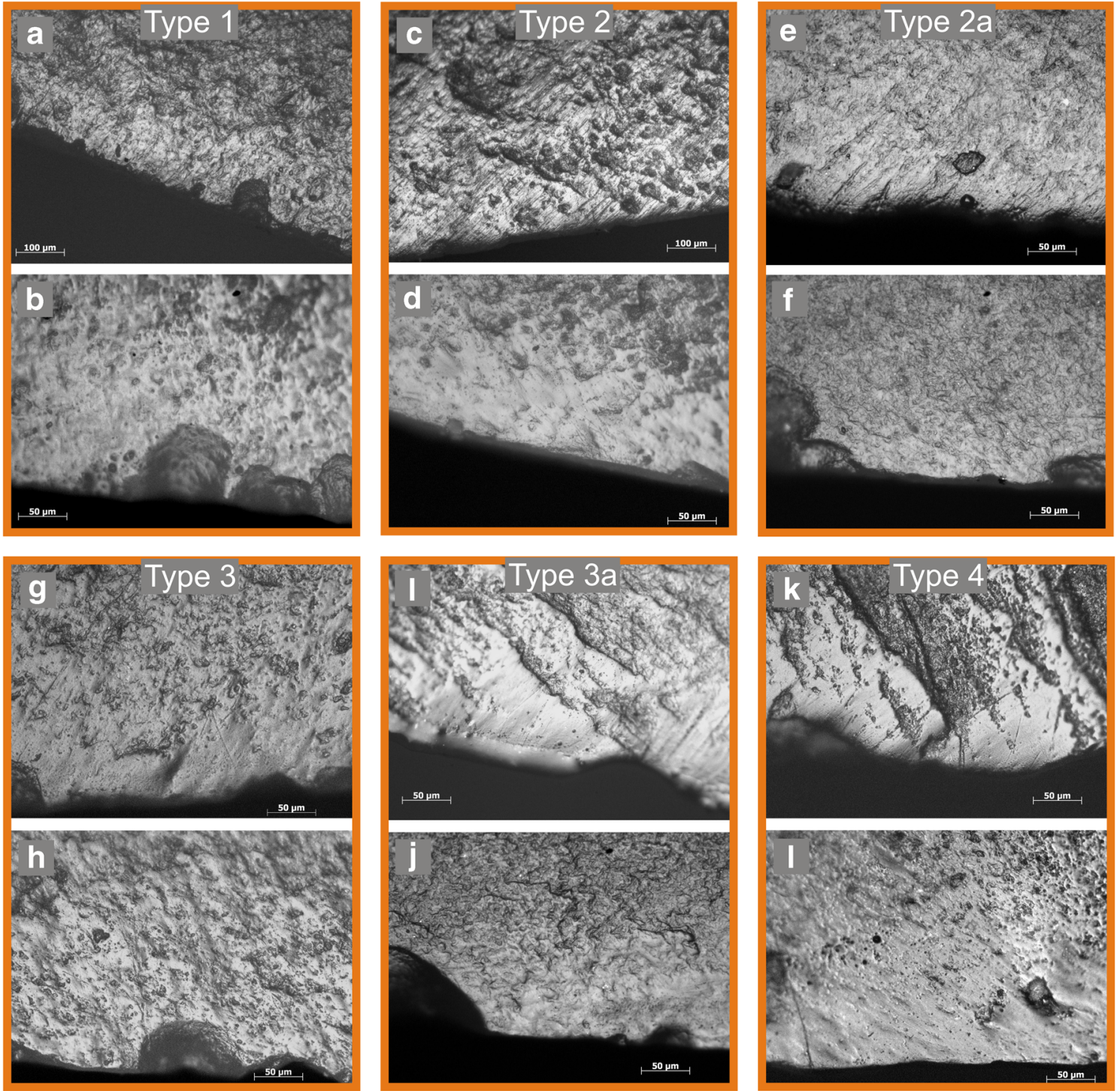

Fig. 3 Variants of polish sets observed on the curved knives of types: 1, 2, 2a, 3, 3a and 4

texture. The polish is accompanied by single, perpendicular linear traces (Fig. 3a).

Polish observed on the dorsal faces is legible as a thin line along the edge, with a degree of intrusion reaching medium extend. It is glossy and has a flat/fluted (in some distance from the cutting edge domed) topography and smooth texture (Fig. $3 b)$. The cutting edge is only slightly rounded or not rounded at all.

In the flint collections analysed here, six tools of this type were identified. One of them was discovered in a collection from Sasieczno, five at the site in Ludowice.

\section{Type 2}

On the ventral faces of the curved knives included in this type occurs a bright polish with a domed topography (flat one only on the cutting edge) and diagonal orientation. The most characteristic here is its very rough texture and the presence of numerous oblique linear traces in the form of black and filled in striations (Fig. 3c). The polish is abrasive and smoothly changes to a surface not covered by wear traces.

On the dorsal faces of the tools of this type, there is glossy, linear polish readable as a thin line along the edge. It has a flat/ fluted (slightly pitted) topography and smooth texture. Linear traces are basically absent. The polished surface is quite abruptly cut off from the non-polished one (Fig. 3d). The cutting edge of the tools is only slightly rounded.

Five curved knives included in this category come from the site in Ludowice and one from site 18 in Lubicz.

\section{Type 2a}

Two artefacts of this type were discovered in the collection from Ludowice, one at the site in Sasieczno and one in Paliwodziźna, 
all of which bear on the ventral faces polish with a characteristic (in general outline) similar to the curved knives of type 2. Their topography, however, is clearly more cratered and therefore similar to the one typical for hide processing (Fig. 3e).

Also, the characteristic of polish observed on the dorsal faces of these artefacts is definitely different from the one typical for tools described above. It is bright, only in some points (at the cutting edge) glossy, has an invasive degree of intrusion and smoothly changes to a non-polished surface. Its topography is domed, only near the cutting edge of it is flat and slightly pitted, and the texture is smooth (Fig. 3f).

It is difficult at this stage in the research to rule out that these are type 2 curved knives, with working edges used for a short time or in a slightly different way, which is why it was decided to label them as sub-type $2 \mathrm{a}$.

\section{Type 3}

Polish legible on the ventral faces of the curved knives of type 3 is visible as a thin line along the edge; however, it can also have an invasive degree of intrusion. It is glossy and has a flat topography, which at a distance from the edge becomes increasingly domed. Its texture is slightly rough (in some points completely smooth). The polish is linear and has diagonal orientation. It is accompanied by single, similarly oriented linear traces (black and filled in striations-Fig. 3g).

Polish characteristic to the dorsal faces of the tools of this type is legible also as a thin line along the edge and can have an invasive degree of intrusion. Very poorly visible, however, is its linearity. The topography is domed and quite pitted, and the texture is smooth. There are no linear traces (Fig. 3h).

The tools of this type were identified mainly from a collection from Ludowice (11 artefacts). One comes from a site in Paliwodzizna.

\section{Type 3a}

Similar to the type 2 and 2a specimens, two curved knives were found in the collection from the Ludowice site, which bear wear traces in some aspects similar to those described in the case of type 3 tools, however, different enough that there may be a reason for creating an independent classification category in the future. A tool of this kind was also probably discovered in the collection from Sasieczno; however, the traces of use discovered on it are too underdeveloped to be confirmed with a high probability.

Polish observed on the ventral faces of these tools is very similar to that described above, but its texture is completely smooth and the polish itself is more 'metallic'. Additionally, its topography is very flat, in the general profile quite similar to the abrasion typical for the curved knives of type 4 that are described below. The cutting edge of the tools is clearly 'melted' and rounded (Fig. 3i).

On the dorsal faces of the specimens of this type polish was observed with a smooth texture, a marginal degree of intrusion and legible as a thin line along the edge. In contrast to the situation recorded in the case of type 3 knives, it is quite clearly cut off from the notpolished surface, its topography is flat (domed in some distance from cutting edge), 'melted', and the profile is slightly linear (Fig. 3j).

\section{Type 4}

On the ventral faces of the curved knives classified as a type 4 can be observed a glossy polish/abrasion with a flat topography, smooth or slightly rough texture and diagonal orientation. It is legible as a thin line along the edge and its degree of intrusion is not higher than medium. In contrast to the situation observed on the type 3 tools, the polish is essentially limited to the area in the immediate vicinity of the cutting edge and rapidly cut off from the unpolished surface (Fig. 3k). It is always accompanied with linear traces in a form of diagonal filled in striations. On the cutting edge itself, there are also single scratches in the form of black striations. Sometimes, they are more numerous and visible also on the side surfaces of the working edge, what makes the texture of polish rougher.

On the dorsal faces of the tools can be observed a bright/ glossy polish with an even invasive degree of intrusion. It has a flat/fluted (quite pitted) topography, in some (quite large) distance from the cutting edge passing into a domed one. It is linear (oriented diagonal) and has a smooth texture (in some points, slightly rough). The polish quite clearly separates from the unpolished surface, although the transition between them is gradual. There are no linear traces (Fig. 31).

The tools of this type were identified only in the collection from Ludowice (eight specimens).

\section{Type 5}

This type is represented by two tools. One was found in the collection from the site in Ludowice; the second was on the site in Paliwodzizna. The polish observed on the ventral faces of these tools is legible as a thin line along the edge and has a degree of intrusion from medium to invasive. It is bright (in some points, slightly glossy) and has a domed topography and smooth texture. The polish is slightly linear (oriented diagonal). There are no linear traces (Fig. 4a).

On the dorsal faces of the tools was observed polish with similar characteristic. However, it has a slightly smaller degree of intrusion (maximum medium), and, what is more important, a pitted (near the cutting edge flat/pitted) topography and with a rough texture. Also, here, there are no linear traces (Fig. 4b). 


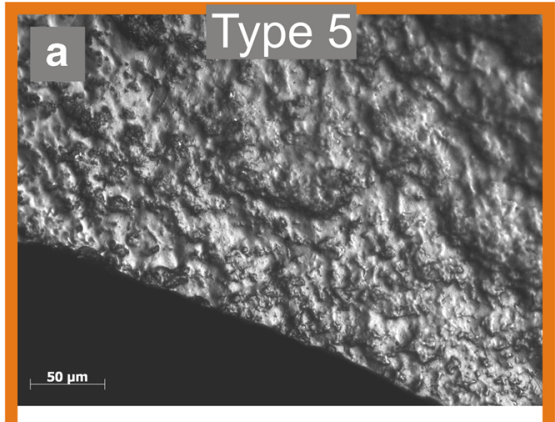

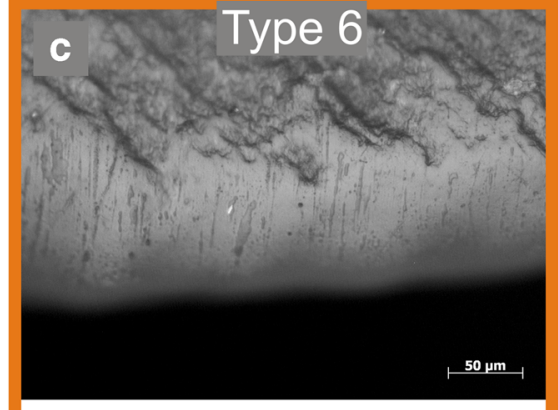

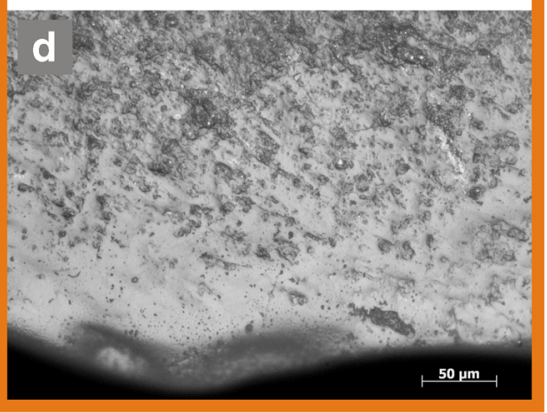

$50 \mu \mathrm{m}$
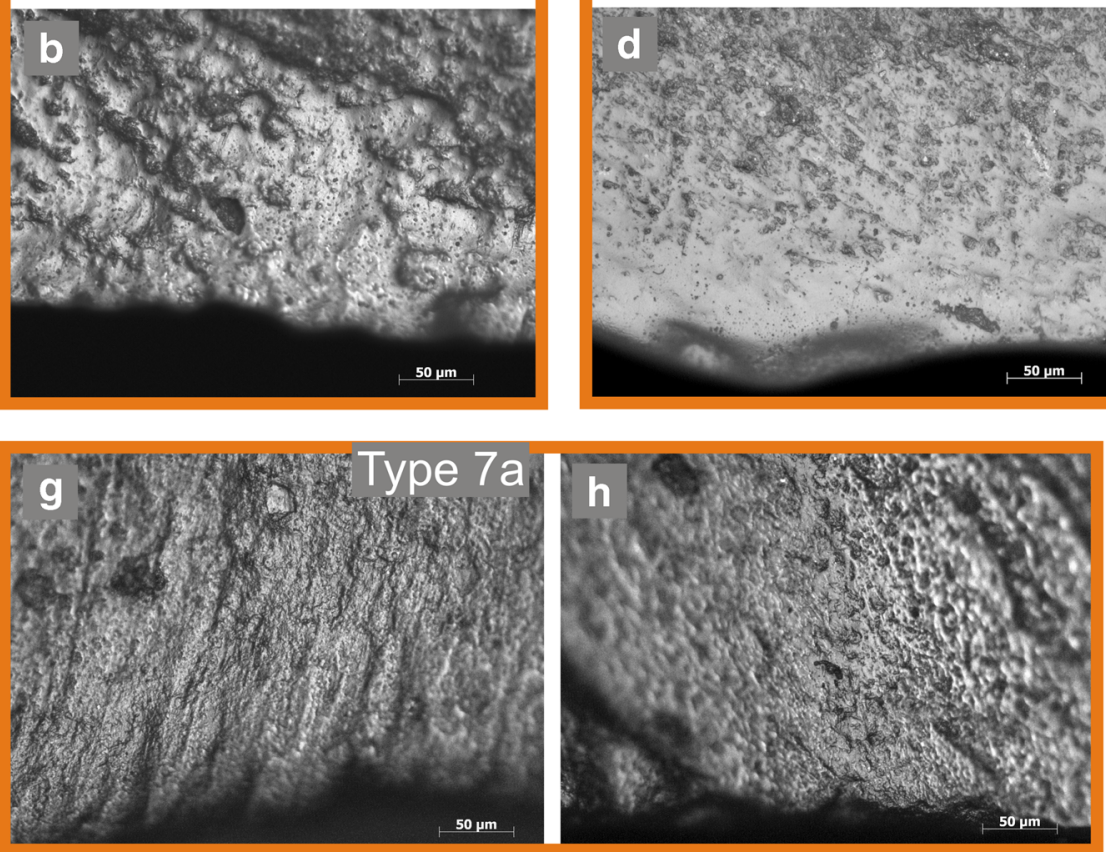
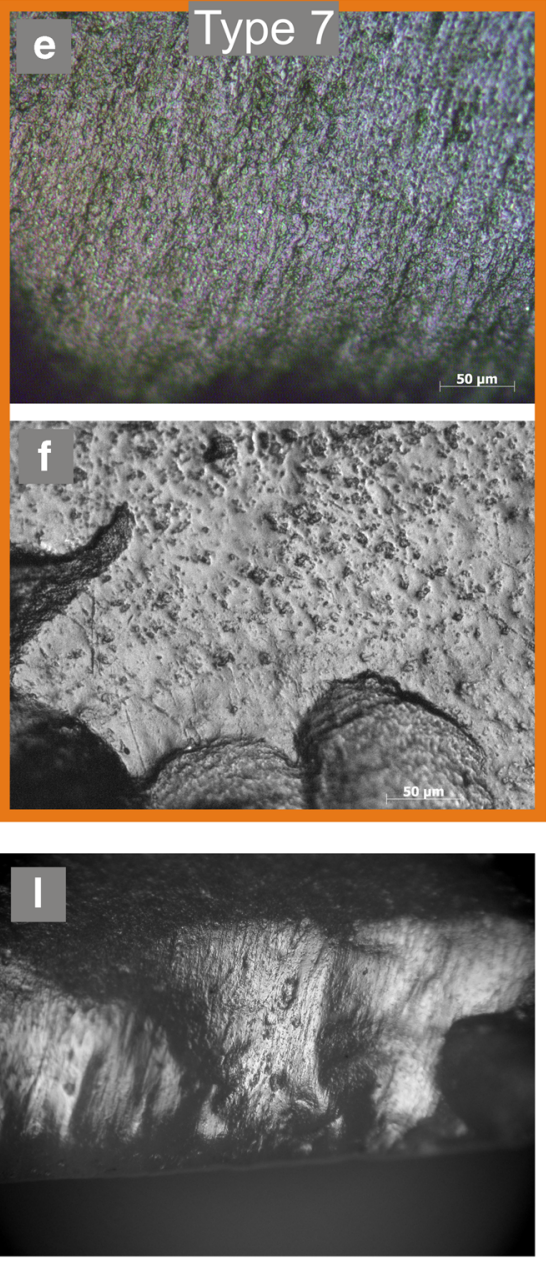

Fig. 4 Variants of polish sets observed on the curved knives of types: 5-7 and 7a (photo a-h) and use-wear traces observed on microdenticulate from site 13 in Lubicz (photo I)

\section{Type 6}

Curved knives of type 6 are represented only by one tool that was discovered in the collection from Ludowice. The polish observed on its ventral side is glossy and has a marginal degree of intrusion (it covers only the cutting edge itself). It has a flat topography and a slightly rough texture with linear traces in a form of delicate scratches (black striations), oriented perpendicularly to the orientation of the tool (Fig. 4c).

The polish discovered on the dorsal face of the specimen has a medium degree of intrusion. It is glossy and has a flat/ pitted (slightly fluted) topography and a generally smooth texture. The polish is linear (oriented diagonal), there are no linear traces (Fig. 4d) and the working edge is rounded.

\section{Type 7}

The polish recorded on the ventral faces of the curved knives of type 7 is different from those described for the types analysed so far. It is matt and has an invasive degree of intrusion, a cratered topography and a rough texture (reminiscent of work on dry hide). It is legible as a band along the edge, which is very rounded. The polish is accompanied with linear traces in a form of diagonal black striations (Fig. 4e).

On the dorsal faces of the tools of this type was observed bright/glossy and slightly linear polish with a medium degree of intrusion and a smooth texture, legible as a thin line along the edge. Its topography is domed, sometimes slightly fluted, but near the cutting edge is flat. Linear traces (diagonal filled in striations) occur only sporadically (Fig. 4f).

The polish observed on curved knives classified as type 7 corresponds to the one classified in the literature as type 23 (van Gijn 1989, 2010). All three tools of this kind were discovered in the materials from the site in Ludowice.

\section{Type 7a}

Use-wear traces identified on the ventral faces of the specimens in this group are similar to those of type 7 . The polish visible here is therefore matt, readable as a thin line or band 
along the edge and has an even invasive degree of intrusion. Its topography is cratered and the texture is rough. It is accompanied by linear traces in a form of slightly diagonal black striations. The working edge is rounded (Fig. 4g).

The polish visible on the dorsal faces of this type of specimen, however, has slightly different characteristics and appears less developed. It is bright and has the character of a thin, sometimes disappearing line along the edge. It covers mostly the higher parts of the microrelief, its topography is domed (in some points passing into the flat) and its texture is slightly rough. In a sense, it is a kind of abrasion of the upper parts of the microrelief. There are no linear traces (Fig. 4h). In addition, atypical spread polish was observed. All four curved knives bearing such traces appeared in the collection from the site in Ludowice.

It cannot be ruled out that specimens of types 7 and 7 a were used for similar activities. Perhaps the usage traces recorded on them occurred even during the same type of activity but illustrate its various stages. The nature of usable traces observed on the dorsal faces of these tools, however, seems to be sufficiently different to treat them independently, at least for now.

A distinct category (type 8) outside the created classification should involve a tool obtained from site 13 in Lubicz (Fig. 2: 19). It is an example of a product referred to by H. Juel Jensen (1994) as microdenticulate, since its blade was made by means of a fine intentional retouch that gave it a microserrated form. It has been suggested that these tools were applied to combing plant fibres for textile production (Juel Jensen 1994). This suggestion can be supported by wear traces visible on the described specimen, whose characteristics and arrangement correspond in general to those visible on the curved knives classified to type 2 (Fig. 4i). However, these cover the entire surface of the intentional retouch negatives without 'overlapping' in an invasive manner with the side edges of the working edge, suggesting that the tool was applied to the processed raw material close to the right angle. This tool is hence clearly different to other specimens of the discussed functional type, since movements performed with it most probably were similar to scraping and not whittling, as in the case of typical curved knives.

\section{Experimental study results}

The programme of experimental studies was based on the findings of studies performed on site 6 in Ludowice, which could be a place specialising in siliceous plant processing. Thus, the location was probably not a coincidence but determined by easy access to the raw material. In this case, such plants should be found in the palynological profile.

In line with the results of the conducted studies of this type, at the time when the Mesolithic settlements in Ludowice were functioning, the prevailing herbaceous plants were sedges
(Cyperaceae) and grasses (Poaceae), which are local species of the peat bog situated here. Ferns (Filicales monolete) and marsh ferns (Thelypteris palustris) are represented and a relatively high and stable curve is created by the eagle fern (Pteridium aquilinum). Wetland plant species are increasingly represented, among which nearly continuous curves are formed by the bogbean (Menyanthes trifoliata), water lilies (Nymphaea), the bur-reed (Sparganium) and the common cattail (Typha latifolia). Of spore plants with a high silica content, the common horsetail (Equisetum arvense) can also be identified in small numbers (Noryśkiewicz report ${ }^{2}$; Osipowicz 2017).

In the experimental programme, the following plant species were taken into account: two sedge species common in Poland, namely the greater tussock-sedge (Carex paniculata) and the lesser pond-sedge (Carex acutiformis), the common cattail (Typha latifolia), the marsh fern (Thelypteris palustris), the eagle fern (Pteridium aquilinum) and the horsetail (Equisetum). Other species identified in the palynological profile proved currently inaccessible or (as in the case of the European white water lily) conservation-dependent.

All plants taken into account in the experimental programme were identified in archaeological contexts and are also used by humans in the present day. The sedge is used for making wattles, ropes and mats. They also serve as an excellent bedding material (Podbielkowski and SudnikWójcikowska 2003). Young common cattail plants are used as fodder. Its shoots, roots and above-ground parts of stems are sometimes eaten as a vegetable, while leaves and flower stems are used for making mats and wattles. The fibre obtained from leaves is turned into ropes. Also, this plant is considered to have therapeutic properties (Podbielkowski and Sudnik-Wójcikowska 2003). These, as well as cosmetic properties, are also ascribed to the common horsetail (Podbielkowski and Sudnik-Wójcikowska 2003) which is collected from May until September and used for treating, among others, neoplasms and eye diseases. It is also believed to strengthen blood vessels and to have anti-haemorrhagic and diuretic properties (Górnicka 2003). The eagle fern, whose remains have been excavated in Mesolithic sites, also has a very wide use (Makohonienko 2000). In the Mesolithic period, its most probable use was, among others, as food (Göranson 1986), the edible parts including starch-rich rhizomes and also young leaves. In present times, its shoots are also used for making fabrics and ropes that are particularly valued for their resistance to moisture (Makohonienko 2000). It also has therapeutic properties. Although the marsh fern has a less broad application, some species of this fern

\footnotetext{
${ }^{2}$ Noryśkiewicz report-Historia roślinności w regionie Ludowic w świetle badań palinologicznych. Description of the results of palynological studies deposited in the Laboratory for the Reconstruction of the Natural Environment, Institute of Archeology of the Nicolaus Copernicus University in Toruń (2015).
} 
have been used to fight worms and ringworm (StichmannMarny and Kretzschmar 1994; Podbielkowski and SudnikWójcikowska 2003). In the Mesolithic, they could have also been used as mattresses (Grøn 1995).

In the course of the study, various parts of plants were subjected to processing. The experiments were more than 60 and up to 90 -min long. For the purpose of the experiment, 10 blades made of Baltic erratic flint of natural straight or slightly concave working edges (analogous to historical products) were used. The blades were knapped from the same nodule of the raw material, and all tools were hafted. The experiments were conducted in a slightly different manner depending on the species of the processed plant (Fig. 5). Experiments which involved splitting the fibres of the greater tussock-sedge and the lesser pond-sedge, as well as splitting leaves of the common cattail, entailed the plants being drawn between the tool blade and the thumb at nearly right angles. The splitting of the stems of the common cattail and the common horsetail was performed by whittling with the angle of contact consistently maintained at $30^{\circ}$. The experimental processing of rhizomes of the common cattail entailed cleaning them from impurities and basal shoots, and then splitting (whittling) into narrow strips. In the course of processing roots of the common horsetail and the eagle fern, two activities were performed. First, they were cleaned of impurities, and then the external wooden parts were gently whittled to reach the soft inner 'flesh'. Processing stems of the eagle fern consisted of removing leaves and then cleaning and splitting (whittling) the stems to obtain fibres. In the course of the experiments on the marsh fern, stems and above-ground parts of stems were processed. The work comprised two activities. The first removed leaves by drawing the stems between the tool blade and the thumb. The second attempted to split the fibres in the stems is by means of whittling to uncover the 'flesh' of the above-ground parts of stems.

As a result of the conducted experiments, highly diverse wear traces were produced (Figs. 6, 7); the characteristics of which are presented in Table 2.

\section{Discussion}

The described experimental work, although based on results of palynological studies, was not able conclusively to identify the plants that were processed using the curved knives. However, the obtained results valuably enabled the elimination of some species. Additionally, on some experimental tools, wear traces similar to those visible on particular types of curved knives were recorded. All these findings give hope that further research will ultimately lead to a solution to plant identity.

As a result of the analysis of findings of the conducted experiments, the following similarities and differences were recorded.

1. Polish of a domed topography recorded on the contact side of the tool used for processing the greater tussock-
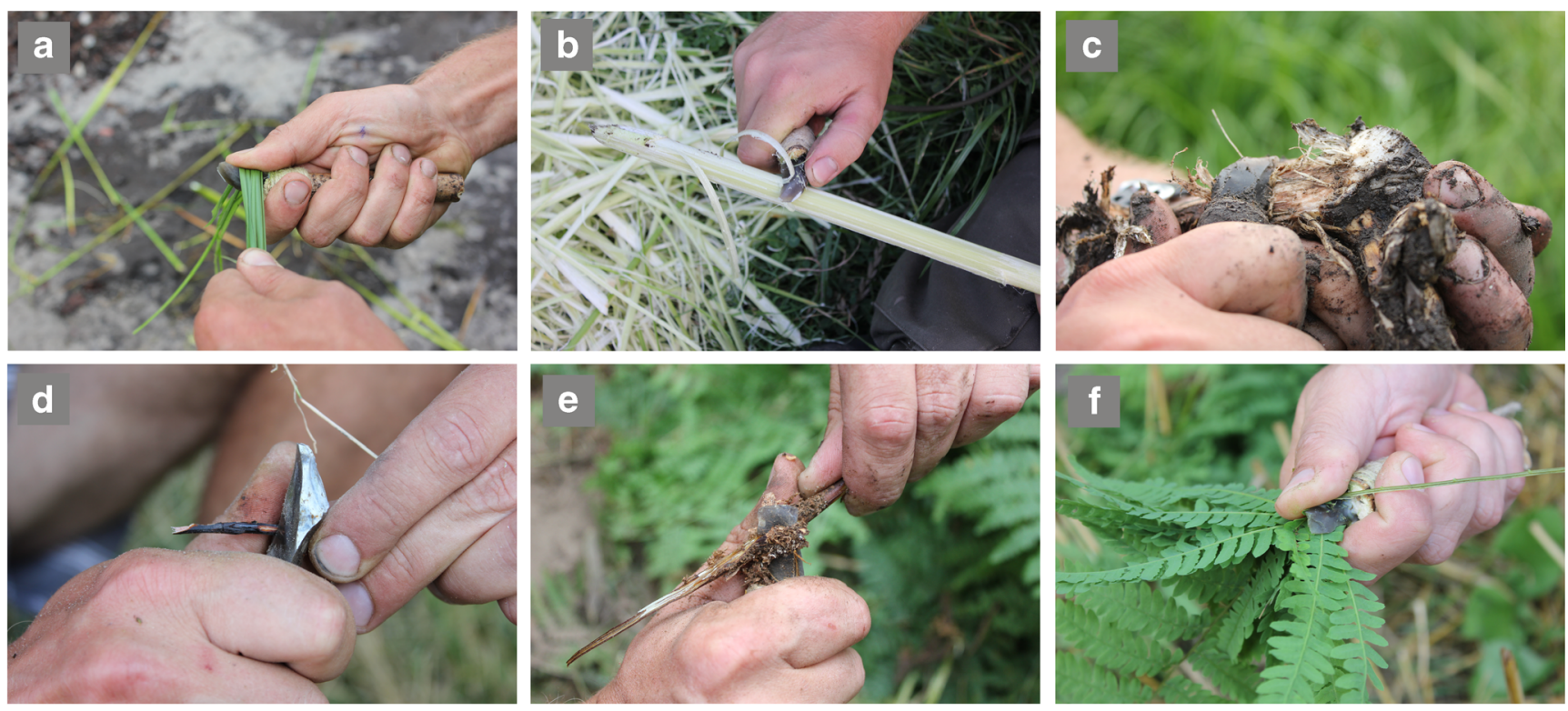

Fig. 5 Examples of experimental work carried out. Processing of a-Carex paniculata, b-stalks of the Typha latifolia, c-rhizomes of the Typha latifolia, d - roots of the Equisetum arvense, e-roots of the Pteridium aquilinum, $\mathrm{f}$ - stalks of the Thelypteris palustris 

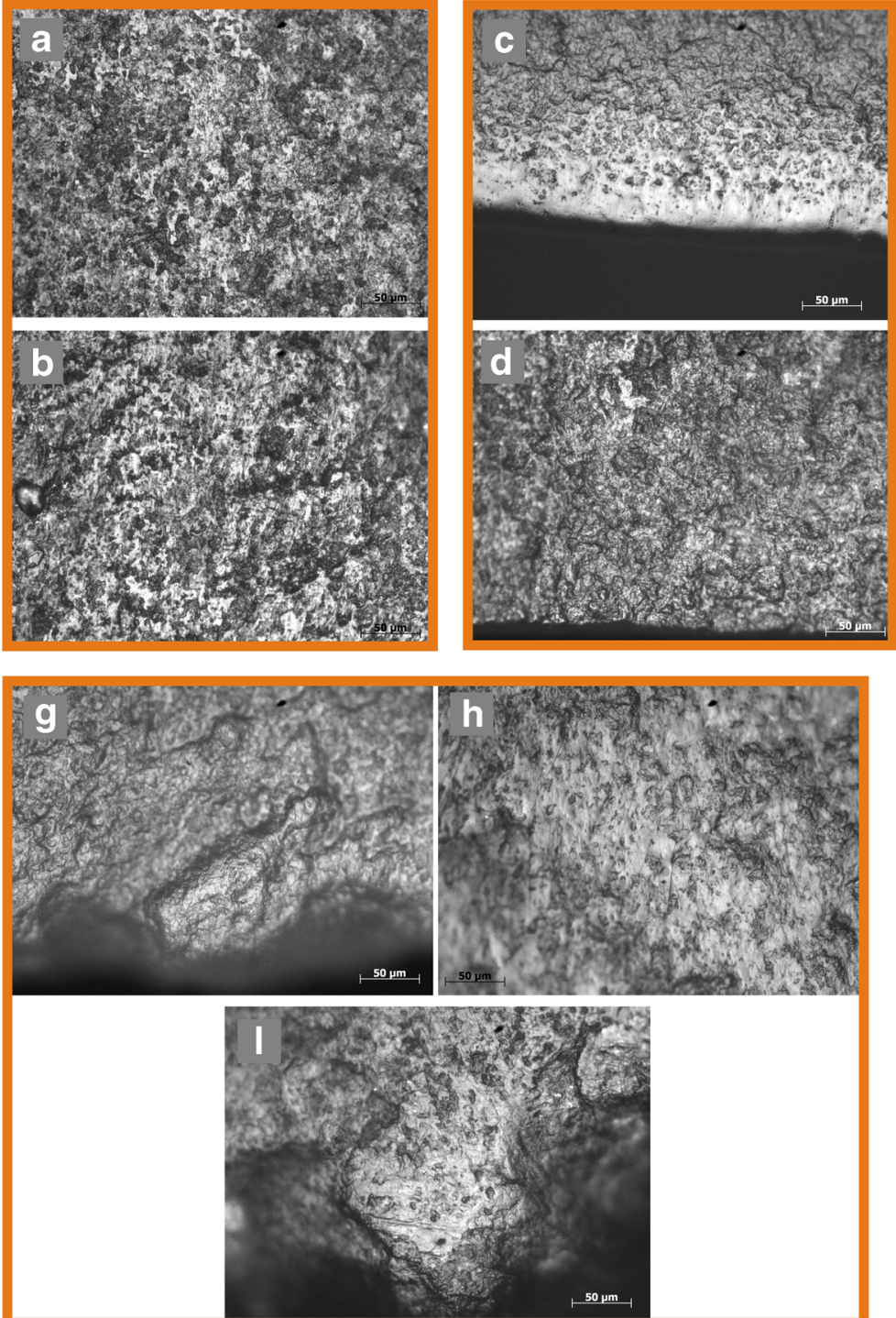
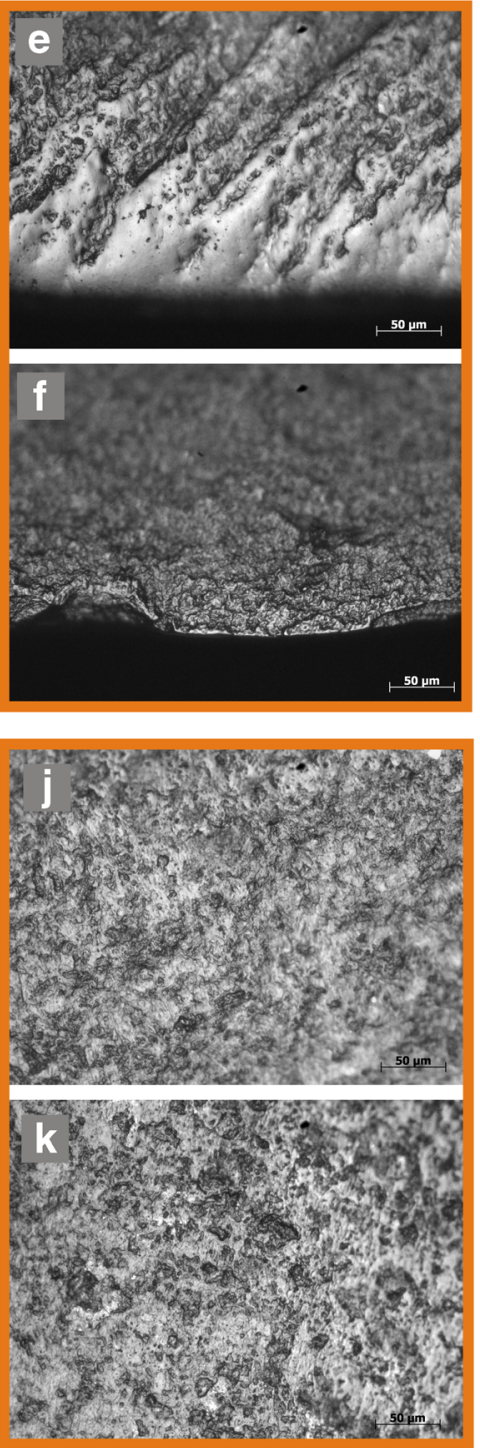

Fig. 6 Variants of polish sets observed on tools used for splitting the fibres: a, b-greater tussock-sedge; c, d-lesser pond-sedge; e, f—stalks of broadleaf cattail; g-i - leaves of broadleaf cattail; j, l—processing of the rhizomes of broadleaf cattail

sedge (Fig. 6a) is similar to that encountered on the negative side of type 7 a curved knives (Fig. 4h). Unfortunately, no other similarities between use-wear traces on these tools were observed.

2. The polish recorded on the contact side of the tool used for processing the lesser pond-sedge (Fig. 6c) is to a large degree analogous to the one characteristic of the negative side of type 1 curved knives (Fig. 3b). The differences between them lie primarily in a slightly different orientation (on the experimental specimen, the polish is more perpendicular) and less rounding of the working edge in the case of the prehistoric specimens. To some extent, similar wear traces were also observed on opposite sides of the working edge on the compared products. The polish formed on the negative side of the specimen used in the experiment bears incipient trace characteristic of the positive side of type 1 knives. It is analogous to the one visible a certain distance from the edge, hence in a location less exposed to quick damage (cf. characteristics of the polish: a domed shape with the microrelief preserved, linearity, low gloss). Obviously, as already mentioned, type 1 curved knives cannot clearly be connected to the lesser pond-sedge processing. The recorded differences are too significant, particularly given that traces are incipient, while this type of polish in a well-developed form was also recorded on other experimental tools (see below, point 3). However, it seems that the considerable similarity between the observed damage may allow future confirmation of the connection between this type of tool and siliceous plant processing (possibly some sedge species) more conclusively through further experiments and analyses. 

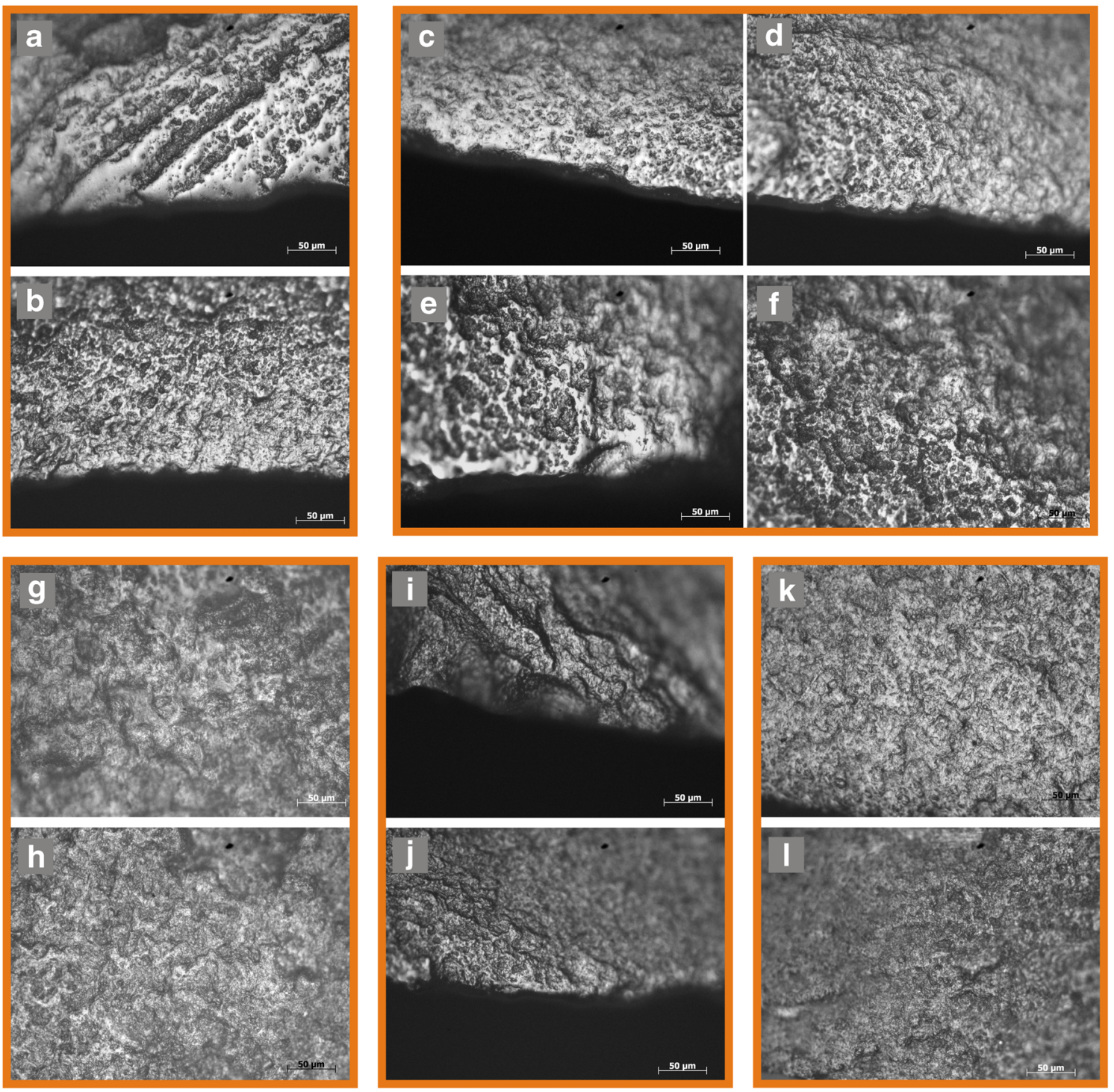

Fig. 7 Variants of polish sets observed on tools used for processing: $\mathrm{a}, \mathrm{b}$ - processing of the stalks of the field horsetail; c-f - roots of the field horsetail; $\mathrm{g}, \mathrm{h}$ — stalks of the eagle fern; i, j—roots of the eagle fern; $\mathrm{k}, \mathrm{l}$ — marsh fern

3. The polish recorded on the positive side of the tool used for the common cattail leaves processing, i.e. a variety visible at a certain distance from the tool blade (Fig. 6h), is identical to the one characteristic of the positive side of type 1 knives (Fig. 3a). However, no other similarities between the use-wear traces on these tools were observed.

4. The polish recorded on the positive side of the experimental tool used for whittling stems of the common cattail (Fig. 6e) is similar to that visible on the positive side of type 3a curved knives (Fig. 3i). Likewise, in this case, no similarities in terms of characteristics of other categories of damage present on these products were observed.

5. The polish visible on the positive side and, particularly, the negative side of the tool used in the experiment that consisted in cleaning and splitting rhizomes of the common cattail (Fig. 6j, k) has much in common with that observed on the negative side of type 7a knives (Fig. 4h). However, there are no further similarities between these products.

6. Wear traces formed on the tool used for splitting stems of the common horsetail are in general similar to those typical of type 3 curved knives. On the positive sides of both these categories of products, polish traces were identified with basically identical characteristics (Figs. 3g, 7a), yet oriented somewhat differently. This is because in the case of the experimental product, its linearity is perpendicular, whereas on the knives, it is at a slightly diagonal. This difference may however stem from minor divergences in how these tools were used.

Against all appearances, the polish identifiable on the negative sides of the compared products is also similar 
Table 2 Characteristics of the use polish observed on the experimental tools

No. Experiment
Characteristics of the polish and linear traces at working edge
Not-contact surface
1 Splitting the fibres of the greater tussock-sedge (Carex paniculata) cattail (Typha latifolia) whittling (splitting) of the stems

4 Processing of the broadleaf cattail (Typha latifolia) splitting the fibres of the leaves

5 Processing of the broadleaf cattail (Typha latifolia) processing of the rhizomes

6 Processing of the field horsetail (Equisetum arvense) - stems

7 Processing of the field horsetail (Equisetum arvense)-roots

Processing of the eagle fern (Pteridium aquilinum) stems
Linear (oriented perpendicular), surface and legible as a band along the working edge. It is visible at some distance from the cutting edge, and its degree of intrusion is invasive. It is bright, but not glossy, its topography is domed and texture is smooth. Linear traces were not observed (Fig. 6a).

Linear (oriented perpendicular), glossy, legible as a thin line along the edge. It has a medium degree of intrusion and a flat topography at a distance from the edge passing into a domed one. Its texture is smooth. Linear traces were not observed (Fig. 6c).

Linear, glossy polish with a medium degree of intrusion, visible as a thin line along the edge. Its topography is flat passing into a domed area, and the texture is smooth. Linear traces were not observed (Fig. 6e).

Two types of polish. The first is on the cutting edge and in its immediate vicinity (thin line along the blade). It has characteristics similar to a polish typical for processing the hide (scraping), so it is linear, oriented perpendicularly and has a cratered topography, and the working edge itself is rounded. This polish, however, is relatively dull (Fig. $6 \mathrm{~g}$ ). The second is at some distance from the edge. It is characterised by an invasive degree of intrusion, flat topography and smooth texture. This polish is bright/glossy, linear (oriented perpendicular), surface and legible as a band. It is accompanied by single linear traces in the form of perpendicular, black striations (Fig. 6h).

Surface polish legible as a band along the edge. It is bright (flashing) and linear (oriented diagonal). Its topography is domed, the texture is slightly rough, and the degree of intrusion is invasive. There are no linear traces (Fig. 6j).

Polish visible as thin line along the edge. It is glossy, linear (oriented perpendicular), with a medium degree of intrusion, flat topography and smooth texture. Linear traces were not observed (Fig. 7a).

Polish legible as a thin line along the edge, glossy, slightly linear (oriented diagonal), with a marginal degree of intrusion. In the areas of the working edge most intensively used, its topography is flat/domed (Fig. 7c); in places less exposed to contact with the processed material, it is domed (Fig. 7d). Polish texture is smooth (in less-used areas slightly rough), linear traces were not observed. Cutting edge is slightly rounded.

Polish legible as a band along the edge. Basically it is matt, slightly linear, has a domed-cratered topography and rough texture (Fig. $7 \mathrm{~g}$ ). It is accompanied by single linear traces in the form of black striations oriented perpendicularly. At the very edge, the polish becomes brighter and its topography more domed.
Linear, oriented perpendicular, legible as a band along the edge but most intensive some distance from it. It is bright and covers mainly the higher parts of the microrelief. It has domed topography and an invasive degree of intrusion. The polish is accompanied by single linear traces in the form of perpendicular, filled in striations. (Fig. 6b).

Legible as a band along the working edge. It is dull, slightly linear (oriented perpendicular). Its topography is cratered, becoming slightly domed. The polish basically does not affect the microrelief image. Its texture is rough (Fig. 6d).

Very poorly readable. Thin line along the edge, a marginal degree of intrusion, bright/glossy, weakly linear. Its topography is atypical and slightly domed (Fig. 6f).

Legible as a thin line along the edge. Its features are largely analogous to those described in the case of the second variation of polish from the contact surface. It is bright, and linear, and its topography is flat, and at a distance from the edge, it becomes increasingly domed. The texture is smooth. The working edge is rounded. The polish is accompanied by single linear traces in the form of perpendicular, black and filled in striations (Fig. 6i).

Identical to the ones observed on the contact surfaces (Fig. 6k).

Polish legible as a band along the edge. It is bright, spread and has an invasive degree of intrusion. Its topography is flat on the cutting edge (while maintaining the general microrelief structure) and strongly pitted. It becomes domed on the side edges. The texture is rough and the cutting edge slightly rounded. There are no linear traces (Fig. 7b).

A developed polish is illegible and observed only at one point. Here, it was very similar to the legible one on the contact surface, only with a much less degree of intrusion. It is glossy and has a domed topography and smooth texture (Fig. 7e). In addition, a linear, bright spread polish with an invasive degree of intrusion, a domed topography and a slightly rough texture was recorded (Fig. 7f).

Polish similar to the one observed on the contact surface. It is dull, scattered with an invasive degree of intrusion. Its topography is cratered/domed and the texture is rough (Fig. $7 \mathrm{~h}$ ). 
Table 2 (continued)

No. Experiment Characteristics of the polish and linear traces at working edge

\begin{tabular}{|c|c|c|c|}
\hline & \\
\hline & & Contact surface & Not-contact surface \\
\hline & $\begin{array}{l}\text { Processing of the eagle fern } \\
\text { (Pteridium aquilinum) - } \\
\text { roots }\end{array}$ & $\begin{array}{l}\text { Polish is shiny, with a marginal degree of intrusion, } \\
\text { readable as a broken line along the cutting edge } \\
\text { (generally underdeveloped). Its topography is } \\
\text { cratered/domed and the texture is smooth. There are } \\
\text { no linear traces (Fig. } 7 \text { i). }\end{array}$ & $\begin{array}{l}\text { Polish with a characteristic very similar to the one } \\
\text { observed on the contact surface. However, its } \\
\text { topography is more domed and pitted and the texture } \\
\text { is rough (Fig. } 7 \mathrm{j} \text { ). }\end{array}$ \\
\hline 10 & $\begin{array}{l}\text { Processing of the marsh fern } \\
\text { (Thelypteris palustris) }\end{array}$ & $\begin{array}{l}\text { Polish readable as a band along the edge. It is bright, } \\
\text { with an invasive degree of intrusion, linear and } \\
\text { oriented diagonal. It has a domed topography and } \\
\text { slightly rough texture (Fig. } 7 \mathrm{k} \text { ). }\end{array}$ & $\begin{array}{l}\text { Polish is scattered, linear (oriented diagonal) and shiny } \\
\text { (more dull than on the contact surface), with a domed } \\
\text { topography. It has an invasive degree of intrusion } \\
\text { and rough texture (Fig. 71). Linear traces were not } \\
\text { observed. }\end{array}$ \\
\hline
\end{tabular}

(Figs. 3h, 7b). In both cases, they are of a domed topography and smooth texture. The main difference is that the polish visible on the prehistoric products is glossier and less pitted. However, it must be borne in mind that the comparison is with a single experimental tool that was used for a relatively short period of time, and as a result, the damage formed on its surface is not very developed. Here, it is worth drawing attention to the fact that on the negative side of type 3 curved knives at a certain distance from their edges (hence, at locations less exposed to damage), polish of basically identical characteristics to those observed on the discussed experimental product can be found. This allows the suggestion that in the initial stages of application, these products could have had similar wear traces. While this suggestion requires further verification, this experimental work has recorded the most significant analogies of wear traces between curved knives and experimental tools to date.

7. Use-wear traces formed in the course of the conducted experimental processing of roots of the common horsetail are not developed enough to allow for a comparative analysis to be performed. Their present characteristics manifest greatest analogies to traces encountered on type 3 curved knives, as in the case of processing stems of the same plant. However, these are only general similarities.

8. As a result of the processing of the eagle fern, wear traces of a clearly different character compared to that typical of the curved knives were formed on the experimental tools.

9. The domed shape of the polish identifiable on the tool used for processing stems of the marsh fern (Fig. 7k, 1) makes them similar to these observed on the positive side of type $7 \mathrm{a}$ knives (Fig. 4h). The characteristics of other features of polish are very different in both cases, nonetheless.

The conducted experimental works proved that processing of even theoretically similar plants may result in wear traces of clearly different characteristics. Such a situation was observed in the case of both sedge species. Interestingly, significant divergence in the formed damage was also obtained by processing different parts of the same plant as during experiments on the common cattail. This leads to a conclusion that the diversity of wear traces encountered when analysing the tools used for processing plants with herbaceous stems is extensive, while the specificity of damage recorded on specific types of curved knives may result from the fact that very specific species were processed or from the use of precisely determined techniques. These can manifest in, for example a polish of 'hide-like' characteristics visible on types 7 and 7 a knives, which was formed during the experiment by splitting the fibres of the common cattail leaves to a very limited extent. It should not be forgotten that some of the types of curved knives may be related to the processing of other materials. This is indicated by a highly abrasive nature of some of the recorded polish traces, most of all, the presence of clear linear traces that could not be replicated despite processing plant roots and rhizomes, which are materials highly contaminated with sand. As noted above, the raw materials identified here as those that could have been subjected to processing in the past are bone and antler, particularly in the case of softening with natural acids and bases. To verify this possibility, for the purpose of the conducted research, tools used in the course of new experiments on methods for softening these raw materials were subjected to use-wear analyses, with full results to be published in the near future. In the experiments, attempts were made to soften bone and antler by boiling in water and soaking in the following substances: water, oxalic acid, lactic acid, lye, urine and flax oil. Due to the specificity of the wear traces recorded on the curved knives, the softened raw material was subjected to whittling and scraping. Each experiment 
took about $60 \mathrm{~min}$. As a result of the use-wear analysis of the employed experimental tools, no wear traces with characteristics typical of curved knives were observed. Therefore, bone and antler can be safely assumed not to be the materials processed using the discussed tools.

\section{Conclusions}

The results of the presented studies explicitly illustrate that the interpretation of the function of the curved knives and the general scale and means of processing plants with herbaceous stems (including siliceous plants) in the Early Holocene are highly complex. As indicated, traces formed on flint tools as a result of working a small selection of plant species prove to have highly different characteristics. Finds from peat bog sites suggest that a considerably wider range of these plant species were subject to processing. An excellent illustration of the range is provided by the equipment found with 'Ötzi the Iceman', which included items made of several dozen plant species (Fleckinger and Steiner 1999; Dickson et al. 2003). The probable scale is also suggested by a number of Early Holocene seasonal camps such as Ludowice which demonstrate a highly specialised plant processing economy. What is needed is more multifaceted and in-depth research, stepping beyond the experimental work and use-wear analyses that are standard in this field into modern botany, studies on plant properties, results of palynological studies and analyses of macro fossils from sites where siliceous plant processing was performed (compare Hurcombe 2008). Lastly, an exceptionally important element of this type of analyses should be analyses of residues present on the actual flint tools. For sure, it should be also conducted some more precise studies in search for correlation between the sets of usage traces observed on each type of curved knives and morphology of the tools (blank type, shape and angle of the working edge, et cetera). However, to make the obtained results statistically reliable, more artefacts representing particular types of curved knives must be gathered before.

The described tools represent one of the first artefacts of this functional type identified in this part of Europe. As with most of their Western European counterparts, they come from sites of the Late Mesolithic chronology. The discovery of such tools in materials from sites in Lubicz, Sasieczno and Ludowice may be therefore (at least for now) an indirect argument in favour of the chronological proximity and correctness of Atlantic dating of these sites, which is especially important for the collection from Sasieczno given no trapezes were found there. The possibility of making such suggestions allows the proposition that products of this type, as well as other functional tools, may soon become not only a priceless source of information about the economy of prehistoric people, but also a relatively good chronology-culture indicator.
This would allow for an explanation of many issues of general nature presently difficult to solve. Of course, we have to remember that in this matter, we are still at the beginning of our way and still a lot can change. As was shown by the use-wear analysis of the Belgian flint collections (Beugnier and Crombé 2005; Beugnier 2007; Guéret 2013), we can expect to identify the curved knives also in the materials from Early Mesolithic sites, which, if confirmed in other parts of Europe, can change to a large extend the way we think about these artefacts. Usewear studies should therefore be continued, and the results used as extensively as possible, including in the analysis of problems hitherto reserved only for technological and typological studies.

Acknowledgments I am very grateful to Amanda Satchell (York University, UK) for the language correction of this article.

Funding information The work was funded by the scientific project from the National Science Center (NCN) in Cracow (Poland) no. 2016/23/B/ HS3/00689.

Open Access This article is distributed under the terms of the Creative Commons Attribution 4.0 International License (http:// creativecommons.org/licenses/by/4.0/), which permits unrestricted use, distribution, and reproduction in any medium, provided you give appropriate credit to the original author(s) and the source, provide a link to the Creative Commons license, and indicate if changes were made.

Publisher's Note Springer Nature remains neutral with regard to jurisdictional claims in published maps and institutional affiliations.

\section{References}

Beugnier V (2007) Préhistoire du travail des plantes dans le Nord de la Belgique. Le cas du Mésolithique ancien et du Néolithique final en Flandre. In: Beugnier V, Crombé P (eds) Plant processing from a prehistoric and ethnographic perspective. Proceedings of a workshop at Ghent University (Belgium) November 28, 2006, vol 1718. BAR International Series, Oxford, pp 23-40

Beugnier V, Crombé P (2005) Étude fonctionnelle du matériel en silex du site mésolithique ancien de Verrebroek (Flandres, Belgique): premiers résultats. Bull Soc Préhist Fr 102(3):527-538

Dickson JH, Oeggl K, Hardy LL (2003) The iceman reconsidered. Sci Am 288(5): 70-80

Fleckinger A, Steiner H (1999) Der Mann aus dem Eis. Bozen-Wien

Göranson H (1986) Man and forests of nemoral broad-leafed trees during the Stone-Age. Striae 24:143-152

Górnicka J (2003) Apteka natury. Poradnik zdrowia. Warszawa

Gramsch B (1992) Friesack mesolithic wetlands. In: Coles B (ed) Wetland revolution in prehistory. Proceedings of a conference held by the Prehistoric Society and WARP at the University of Exeter, April 1991 (London 1992), pp 65-72

Grøn O (1995) The Maglemose Culture. The reconstruction of the social organization of a Mesolithic culture in Northern Europe. BAR International Series 616, Oxford

Guéret C (2013) Character and variability of Early Mesolithic toolkits in Belgium and Northern France: the contribution of a functional approach Mesolithic. In: Valentin B, Souffi B, Ducrocq T, Fagnart JP, Séara F, Verjux C (eds) Mesolithic Palethnography, Research on 
open-air sites between Loire and Neckar. Société préhistorique française, Paris, pp 147-167

Guéret C, Gassin B, Jacquier J, Marchand G (2014) Traces of plant working in the Mesolithic shell midden of Beg-an-Dorchenn (Plomeur, France). Mesolithic Miscellany 22(3):3-15

Hurcombe L (2008) Organics from inorganics: using experimental archaeology as a research tool for studying perishable material culture. World Archaeol 40(1):83-115

Juel Jensen H (1994) Flint tools and plant working: hidden traces of stone age technology: a use wear study of some Danish Mesolithic and TRB implements. Åarhus Unversity Press, Åarhus

Little A, van Gijn A (2017) Enigmatic plant-working tools and the transition to farming in the Rhine/Meuse Delta. Analecta Praehistorica Leidensia 47:1-11

Lozovski VM, Lozovskaya OV, Conte IC, Maigrot Y, Gyria E, Radu V, Desse-Berset N, Ballbé EG (2013) Fishing in the late Mesolithic and early Neolithic of the Russian Plain: the case of site Zamostje 2. In: Lozovski VM, Lozovskaya OV, Conte IC (eds) Zamostje 2. Lake settlement of the Mesolithic and Neolithic fisherman in upper Volga region. St. Petersbourg, pp 19-45

Makohonienko M (2000) Przyrodnicza historia Gniezna. BydgoszczPoznań

Osipowicz G (2010) Narzędzia krzemienne w epoce kamienia na ziemi chełmińskiej. Studium traseologiczne. Nicolaus Copernicus University Press, Toruń

Osipowicz G (2015) Zorganizowane i wyspecjalizowane obozowisko zbieraczy? Z wyników badań traseologicznych i przestrzennych materiałów mezolitycznych ze stanowiska Ludowice 6. Przegląd Archeologiczny 63:59-85

Osipowicz G (2017) Społeczności mezolityczne Pojezierza ChełmińskoDobrzyńskiego. Próba modelowej analizy wieloaspektowej funkcji i organizacji przestrzennej wybranych obozowisk. Nicolaus Copernicus University Press, Toruń
Osipowicz G (2018) Ludowice 6 site, western habitation: a silica plant processing female gatherer campsite? J Archaeol Sci Rep 18:960-972

Osipowicz G, Jankowski M, Makowiecki D, Weckwerth P (2014) Obozowiska mezolityczne ze stanowiska Ludowice 6, powiat wąbrzeski, siedlisko zachodnie. Wiadomości Archeologiczne 65: 149-196

Podbielkowski Z, Sudnik-Wójcikowska B (2003) Słownik roślin użytkowych. Warszawa

Pyżewicz K (2013) Inwentarze krzemienne społeczności mezolitycznych w zachodniej części Niżu Polskiego. Analiza funkcjonalna. Archaeological Foundation Press, Zielona Góra

Sobkowiak-Tabaka I, Kufel-Diakowska B (2018) The shining piece of puzzle: evidence of plant use in the Late Palaeolithic. Archaeol Anthropol Sci. https://doi.org/10.1007/s12520-018-0604-z

Stichmann-Marny U, Kretzschmar E (1994) Przewodnik rośliny i zwierzęta. Warszawa

Taylor M, Bamforth M, Robson HK, Watson C, Little A, Pomstra D, Milner N, Carty JC, Colonese AC, Lucquin A, Allen S (2018) The wooden artefacts. In: Milner N, Conneller C, Taylor B (eds) Star Carr Volume 2, Studies in Technology, Subsistence and Environment. White Rose Press, York, pp 367-418

van Gijn AL (1989) The wear and tear of flint. Principles of functional analysis applied to Dutch Neolithic assemblages. Analecta Praehistorica Leidensia 22. Leiden University, Leiden

van Gijn AL (2010) Flint in focus. Lithic biographies in the Neolithic and bronze age. Sidestone Press, Leiden

Vaughan PC (1985) Use-wear analysis of flaked stone tools. The University of Arizona Press, Tucson

Vaughan PC, Bocquet A (1987) Première etude fonctionelle d'outils lithiques néolithiques du village de Charavines, Isère. L'Antropologie 91:399-410

Zhilin MG (2014) Early Mesolithic hunting and fishing activities in Central Russia: a review of faunal and artefactual evidence from wetland sites. J Wetland Archaeol 14:92-106 